\title{
Current and emerging testosterone therapies for male hypogonadism
}

This article was published in the following Dove Press journal:

Research and Reports in Endocrine Disorders

7 April 2015

Number of times this article has been viewed

\section{Blake Wynia' \\ Jed C Kaminetsky²}

'Department of Urology, New York University Langone Medical Center, 'University Urology Associates, Manhattan Medical Research, New York, NY, USA
Correspondence: Jed C Kaminetsky University Urology Associates, Manhattan Medical Research, 215 Lexington Ave, Floor 20, New York, NY, I0016, USA $\mathrm{Tel}+\mathrm{I} 2126869015$

Fax +I 2126868607

Email jckammd@att.net

\begin{abstract}
Exogenous testosterone was introduced nearly 80 years ago as a pharmaceutical agent to treat male hypogonadism. Researchers continue to enhance the pharmacokinetic profile of testosterone to improve various benefits, including mood and sexual function, among other potential benefits. The modalities that are currently available include implants, intramuscular injections, oral formulations, transdermal delivery systems (ie, patches, gels, and a solution), transbuccal delivery systems, and most recently, intranasal testosterone. Each of these products differs by the delivery system, half-life, and ability to mimic physiological levels of testosterone. While we recognize the unique characteristics and benefits of existing agents, we must address unmet needs, including how best to mimic physiological levels of testosterone and how to administer it through a more effective, safe, and convenient mechanism. In our overview of current and emerging testosterone therapies, we will examine these topics and address the controversy of prostate cancer and cardiovascular risk.
\end{abstract}

Keywords: hypogonadism, low testosterone, testosterone replacement therapy, cardiovascular

\section{Introduction}

Testosterone is the essential androgen for male reproductive function that allows for the development of external genitalia and secondary sex characteristics in prepubescent males, and the maintenance of secondary sex characteristics, initiation and maintenance of spermatogenesis, and stimulation and maintenance of sexual function in postpubescent males. ${ }^{1,2}$ When the testes fail to produce an adequate amount of testosterone and/ or to conduct normal spermatogenesis, the result is hypogonadism. ${ }^{1}$

Hypogonadism is caused by a disruption of at least one level of the hypothalamicpituitary axis, and is classified based on where this disruption occurs - either primary (affecting the testes) or secondary (affecting the pituitary or hypothalamus). ${ }^{1,3}$ Primary hypogonadism, characterized by low serum testosterone and elevated luteinizing hormone and follicle-stimulating hormone, can result from chromosomal defects, such as Klinefelter's syndrome or direct testicular injury (eg, radiation, chemotherapy, surgery). ${ }^{1}$ Secondary hypogonadism, characterized by low serum testosterone, luteinizing hormone, and follicle-stimulating hormone, can be attributed to disease (eg, Prader-Willi syndrome) or direct injury to the hypothalamus or pituitary gland (eg, tumors, radiation). ${ }^{1}$

The cause of late onset hypogonadism, or age-related decline in testosterone levels, is multifactorial and likely due to a combination of primary (testicular) and secondary (hypothalamic) mechanisms. ${ }^{4}$ In healthy young males, serum testosterone levels range 
from 300 to $1,000 \mathrm{ng} / \mathrm{dL}$, but as men age, these levels have been shown to decline by up to $2 \%$ each year. ${ }^{5-7}$

Hypogonadism is one of the most common endocrinopathies. ${ }^{8}$ In the US alone, it affects an estimated 4-5 million males, or one in every 16 men aged 30-79 years. ${ }^{9-11}$ It can manifest in all age groups, but is most prevalent in older males, affecting approximately $20 \%$ of men in their $60 \mathrm{~s}, 30 \%$ in their $70 \mathrm{~s}$, and $50 \%$ in their $80 \mathrm{~s} .{ }^{5,9}$ The aging population is expected to further increase the burden of this disorder. ${ }^{9}$

Diagnosis of hypogonadism involves a thorough assessment of symptoms combined with accurate assay of serum testosterone. ${ }^{4}$ Symptomatic presentation tends to vary depending on the patient's age. In prepubescent males, hypogonadism is associated with delayed puberty, gynecomastia, fatigue, increased body fat, decreased body hair, shorter penile length $(<5 \mathrm{~cm})$, high-pitched voice, small testes (volume $<20 \mathrm{~mL}$ ), and/or decreased or absent scrotal rugae and hyperpigmentation. Postpubertal males may present with sexual dysfunction, low libido, fatigue, depressed mood and affect, oligospermia or azospermia, loss of body hair, gynecomastia, anemia, and hot flashes, and decreased lean body mass and muscle strength, testicular volume, and bone mineral density, among other symptoms. ${ }^{4,12,13}$ These symptoms have been shown to adversely affect multiple organ systems, reduce quality of life, and increase mortality. ${ }^{14,15}$ Clinicians should recognize

the signs and symptoms of hypogonadism and test serum testosterone levels.

Testosterone levels fluctuate diurnally and, thus, an initial measurement of testosterone is recommended in the morning when circulating testosterone levels are highest and it becomes easier to distinguish subnormal levels. Although reference ranges at laboratories may vary, many clinicians, including the Endocrine Society, consider $300 \mathrm{ng} / \mathrm{dL}$ or 10.4 $\mathrm{nmol} / \mathrm{L}$, the lower limit of normal. ${ }^{3}$ When subnormal testosterone levels are detected, it is recommended that testosterone measurements are repeated to confirm a diagnosis. ${ }^{3}$

In addition to lifestyle changes, including improvements in diet, exercise, and sleep, restoring testosterone levels to within the normal range with testosterone replacement therapy (TRT) can improve many of the effects of hypogonadism. ${ }^{16-20}$ Testosterone was first synthesized approximately 80 years ago and was introduced as subdermal testosterone implants shortly thereafter (Figure 1). ${ }^{8}$ Since then, a number of other modalities have become available, offering patients various benefits, including enhancements in mood and sexual function, among others (Figure 2). ${ }^{21-27}$ Although testosterone therapy has effectively treated hypogonadism for decades, there remains an unmet need for new therapies that are simple and convenient to administer/use, safe, and mimic physiological levels of testosterone. This review will discuss current and emerging testosterone-based therapies for hypogonadism, as well as address recent controversy regarding prostate cancer

(2010)

Testosterone solution

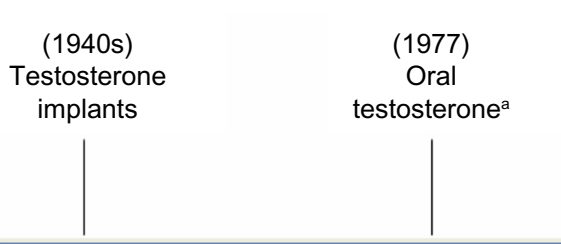

(2000) SC self-administered testosterone, Testosterone oral testosterone undecanoate, gel testosterone gel 1940s 1950s 1960s 1970s 1980s 1990s 2000s 2010s

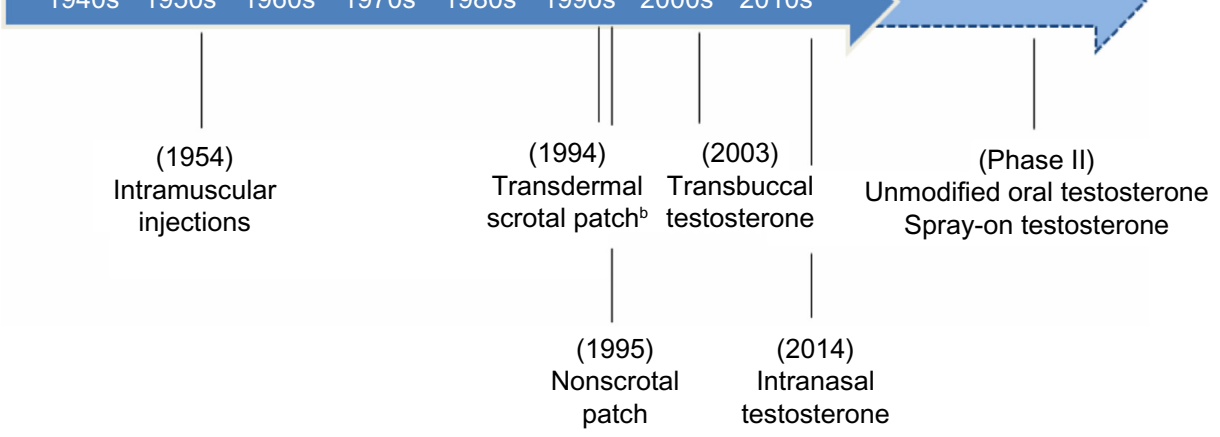

Figure I History of testosterone therapy.

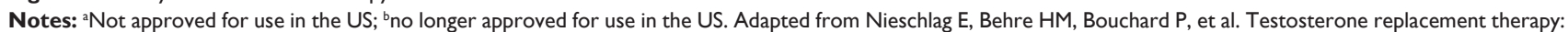
current trends and future directions. Human Reproduction Update. 2004; I0(5):409-4I9, by permission of Oxford University Press ${ }^{19}$ and Pfeil E, Dobs AS. Current and future testosterone delivery systems for treatment of the hypogonadal male. Expert Opinion on Drug Delivery. 2008;5(4):47I-48I, copyright @ 2008, Informa Healthcare. Reproduced with permission of Informa Healthcare. ${ }^{28}$

Abbreviation: SC, subcutaneous. 


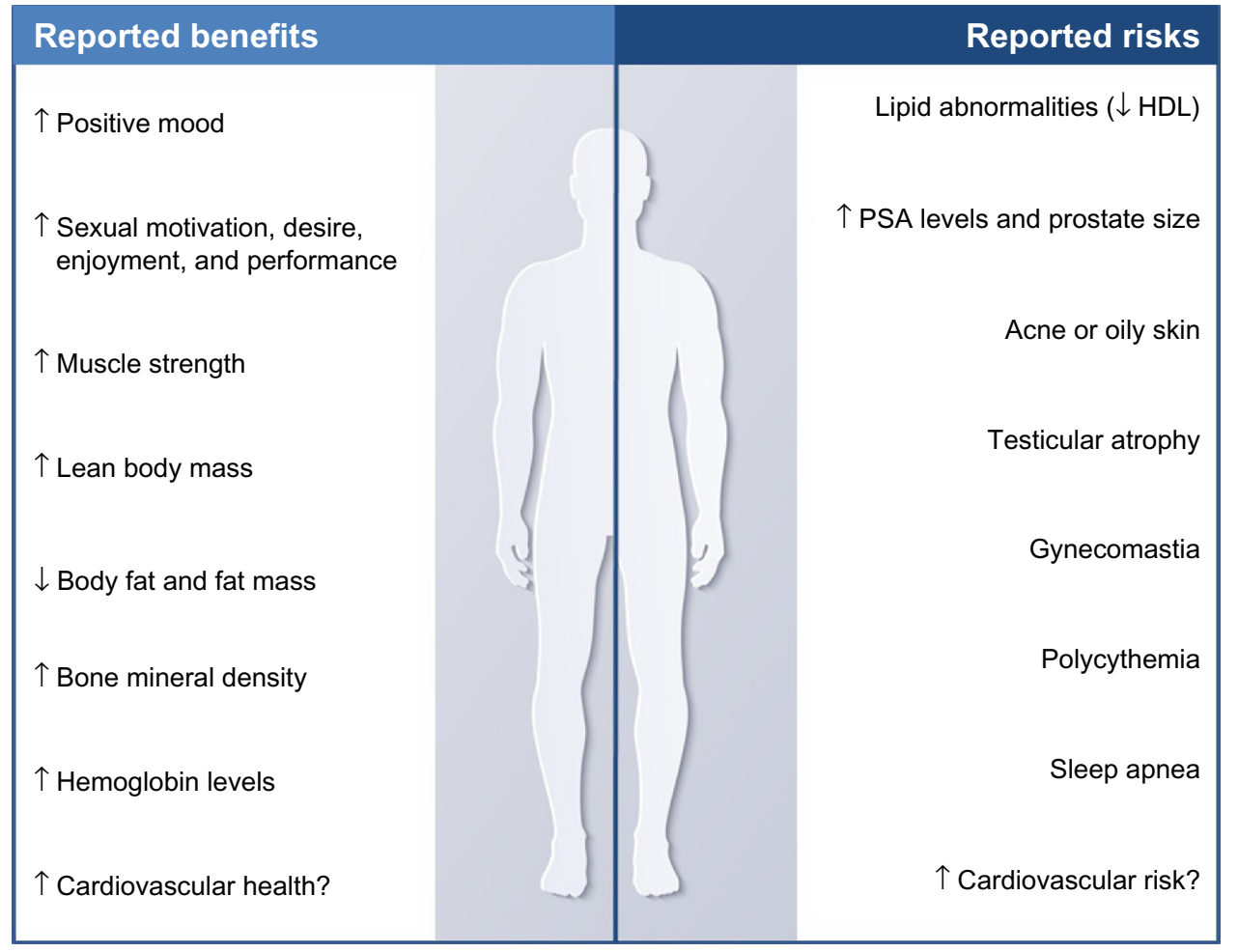

Figure 2 Clinically significant effects of testosterone replacement.

Note: Adapted from Pfeil E, Dobs AS. Current and future testosterone delivery systems for treatment of the hypogonadal male. Expert Opinion on Drug Delivery. 2008;5(4): 47I-48I, copyright (C 2008, Informa Healthcare. Reproduced with permission of Informa Healthcare ${ }^{28}$ and Edelstein D, Sivanandy M, Shahani S, Basaria S. The latest options and future agents for treating male hypogonadism. Expert Opinion on Pharmacotherapy. 2007;8(I7):299I-3008, copyright @ 2007 , Informa Healthcare. Reproduced with permission of Informa Healthcare. ${ }^{4}$ Image $@$ iStock.com/alexandragll .

Abbreviations: $\uparrow$, increased; $\downarrow$, decreased; HDL, high-density lipoprotein; PSA, prostate-specific antigen.

and cardiovascular $(\mathrm{CV})$ risk associated with testosterone replacement. Other nontestosterone therapies are available or are in development for the treatment of hypogonadism, such as selective androgen receptor modulators, aromatase inhibitors, selective estrogen receptor modulators, and human chorionic gonadotropin. However, nontestosterone therapies are beyond the scope of this review and have been summarized elsewhere. ${ }^{4,28,29}$

\section{Current testosterone therapy}

Native testosterone is well-absorbed by the intestine; however, it is metabolized rapidly by the liver, which presents

Table I Testosterone therapies by formulation/route

\begin{tabular}{|c|c|c|}
\hline Formulation/route & Dosing ranges & Dosing frequency \\
\hline Testosterone implants ${ }^{30}$ & $150-450 \mathrm{mg}$ & Every 3-6 months \\
\hline \multicolumn{3}{|l|}{ Intramuscular injections } \\
\hline Testosterone esters ${ }^{89}$ & $50-400 \mathrm{mg}$ & Every $2-4$ weeks \\
\hline Testosterone undecanoate ${ }^{34,35}$ & $\begin{array}{l}750 \mathrm{mg} \text {, and then } 750 \mathrm{mg} 4 \text { weeks later, and then } 750 \mathrm{mg} \\
\text { every } 10 \text { weeks thereafter; I,000 mg every I0-14 weeks }\end{array}$ & Every $10-14$ weeks \\
\hline Oral $^{36}$ (not United States Food and Drug & I20-160 mg daily, in two divided doses, for the & Once to twice a day \\
\hline Administration-approved) & first $2-3$ weeks. Then, $40-120$ mg daily & \\
\hline \multicolumn{3}{|l|}{ Transdermal } \\
\hline Testosterone patch ${ }^{37}$ & $2-6 \mathrm{mg}$ & Once daily \\
\hline \multirow[t]{3}{*}{ Testosterone gel ${ }^{39,90,91}$} & $50-100$ mg (I\% gel) & Once daily \\
\hline & $20.25-81 \mathrm{mg}(\mathrm{I} .62 \%$ gel $)$ & \\
\hline & $10-70 \mathrm{mg}(2 \%$ gel $)$ & \\
\hline Testosterone solution ${ }^{42}$ & $60-120 \mathrm{mg}$ & Once daily \\
\hline Transbuccal $^{44}$ & 30 mg & Two times a day \\
\hline Intranasal testosterone ${ }^{48}$ & II mg & Three times a day \\
\hline
\end{tabular}


challenges with maintaining normal serum levels in hypogonadal patients. ${ }^{4}$ In an effort to improve bioavailability, pharmacokinetics, and therapeutic efficacy, developers have modified the molecular structure of testosterone and developed a variety of formulations and delivery routes (Table 1).

\section{Implants}

Introduced in the 1940s, testosterone implants were the first form of exogenous testosterone therapy. ${ }^{4}$ Although the treatment is approved by the US Food and Drug Administration (FDA) for $150-450 \mathrm{mg}$ (two to six $75 \mathrm{mg}$ pellets) every 3-6 months, clinicians most commonly use 10-12 pellets every 4 months. ${ }^{29,30}$ To administer testosterone implants, the pellets are inserted subcutaneously using a small trocar. Retention sutures are occasionally used to hold the pellets in place. Erosion at the surface of the pellet leads to its systemic absorption. ${ }^{28}$ Serum testosterone concentrations reach a peak during the first month and then decline steadily into the hypogonadal range. ${ }^{8}$ Implants have been shown to normalize testosterone and provide long-lasting symptom improvements for up to 6 months with mid- to high-range testosterone levels achieved in the body. ${ }^{31,32}$ Adverse events (AEs) include rare cases of spontaneous extrusion at the insertion site and surgical side effects, such as bleeding or infection. ${ }^{8,28}$

\section{Intramuscular (IM) injections}

Injectable testosterone first became available in the $1950 \mathrm{~s}$ with the development of testosterone esters, including testosterone cypionate, testosterone enanthate, and testosterone proprionate. ${ }^{19,28}$ IM injections of testosterone esters are a widely prescribed testosterone therapy due to low cost of treatment and convenience of infrequent dosing. ${ }^{19,28}$ Esterification at the testosterone molecule and emulsification in oil further increases the half-life and allows for a long duration of action. ${ }^{19,28}$

Testosterone cypionate and testosterone enanthate are administered every 2-4 weeks, while testosterone propionate is administered 2-3 times per week. ${ }^{19,28}$ Although pharmacodynamics vary, in general, IM injection of testosterone esters leads to supraphysiological serum testosterone levels after 24 hours and subphysiological levels toward the end of the dose interval. ${ }^{19,28}$ This may lead to side effects such as mood swings, as well as variability in libido, sexual function, and energy levels. ${ }^{19,28}$ Additionally, this delivery system requires deep injection, and injection site reactions are common with IM-delivered testosterone. ${ }^{19,28}$

An additional ester, testosterone undecanoate (TU), offers a prolonged half-life as compared to other esters, which allows the drug to be administered every 10-14 weeks. ${ }^{4,28,33-35}$ Furthermore, serum testosterone is consistently maintained within the physiological range. ${ }^{4}$ As a result, patients report fewer side effects, including fewer mood swings and more stable libido. Side effects associated with TU include gynecomastia and breast tenderness. ${ }^{4}$ Additionally, prostate-specific antigen (PSA) levels and prostate size have reportedly increased among elderly males; however, these levels were not found to exceed normal levels., ${ }^{4,28}$

\section{Oral formulations}

Oral testosterone first became available in the 1970s; however, it is not yet approved for use in the US. Although used outside of the US for over 3 decades, oral preparations of testosterone esters, including TU, are associated with undesirable dosing and side effects. ${ }^{4,8} \mathrm{TU}$ is administered up to three times daily, must be administered with fatty meals to allow absorption, and has a relatively unpredictable absorption pattern, resulting in short-lived peaks following ingestion. ${ }^{4,8,36}$ Because TU undergoes absorption in part through the intestinal lymphatic pathway, it circumvents first-pass metabolism through the liver. ${ }^{36}$ Long-term use is safe and well tolerated; however, nausea and gastrointestinal effects have been reported. ${ }^{4}$ Presently, available oral preparations are recommended for patients with mild decreases in testosterone. ${ }^{4}$

\section{Transdermal delivery systems}

Due to the lipophilic nature of testosterone, the molecule readily crosses skin and into circulation. ${ }^{4}$ Transdermal delivery of testosterone allows for the maintenance of serum testosterone levels that are physiologic, and minimizes fluctuations seen with testosterone esters. ${ }^{4}$ Although transdermal delivery requires daily administration and is more expensive than IM testosterone, it is the treatment of choice for many patients. ${ }^{4}$

\section{Testosterone patch}

In 1994, scrotal films became the first transdermal testosterone preparation; however, they were quickly superseded by nonscrotal patches once they became available. ${ }^{8}$ Nonscrotal patches contain testosterone in a reservoir with permeationenhancing agents and are typically applied to the back, abdomen, thighs, or upper arms. ${ }^{4,37}$ They are available in various sizes, which may be combined to achieve the most appropriate dose for the patient. Patches have been shown to mimic normal circadian variations of serum testosterone and dihydrotestosterone levels of healthy men, thereby resulting in improvements in mood, fatigue, and sexual function. ${ }^{4,37,38}$ The most common adverse reactions ( $\geq 3 \%$ of patients) 
include pruritus $(37 \%)$, blistering $(12 \%)$, erythema $(7 \%)$, and vesicles $(6 \%)$ occurring at the site of application. Other adverse reactions include prostate abnormalities (5\%), headache (4\%), allergic contact dermatitis (4\%), site burning at the application site $(3 \%)$, skin induration $(3 \%)$, and depression $(3 \%){ }^{37}$

\section{Testosterone gel}

Testosterone gel, which was first approved in 2000, has become a popular choice for many patients due to simple once-daily application and maintenance of physiologic testosterone levels., ${ }^{4,28}$ When applied in the morning, testosterone gel results in physiological serum levels, mimicking normal diurnal rhythm. ${ }^{8}$ Gels ( $\geq 67 \%$ ethanol by volume with permeation enhancers) are applied to clean, intact skin of the shoulders, upper arms, or abdomen and typically dry 10-15 minutes after application; however, it takes longer for the testosterone to fully absorb. ${ }^{4}$ Similar to patch preparations, gels offer flexible dose modifications. ${ }^{39}$ Studies have shown gels to effectively restore and maintain constant steady-state testosterone levels, thereby improving sexual function, mood, and body composition..$^{21,23,27,40}$ Gels are generally well tolerated - the most common $\mathrm{AE}$ is skin irritation at the application site; ${ }^{39}$ however, skin irritation occurs less frequently with gels than with patches. All gels include a boxed warning for transference, or secondary exposure, and it is therefore recommended that patients avoid skin-to-skin contact with others, particularly women and children, following administration. ${ }^{39}$

\section{Testosterone solution}

Testosterone solution first became available in $2010 .{ }^{41}$ It is the only underarm testosterone therapy, and is applied directly to the underarm without rubbing into the skin with fingers or hands. ${ }^{42}$ Application of deodorant or antiperspirant is recommended at least 2 minutes prior to applying the topical solution. Two pump actuations, or $60 \mathrm{mg}$, of testosterone solution is administered once daily. The dose can be titrated up or down as needed to ensure desired concentrations are achieved. Testosterone solution is generally well tolerated; most common adverse reactions (incidence $>4 \%$ ) reported after 180 days were skin application site reactions (eg, application site irritation, 8\%; application site erythema, 7\%), increased hematocrit $(7 \%)$, headache $(6 \%)$, diarrhea $(4 \%)$, vomiting (4\%), and increased serum PSA (4\%). ${ }^{42}$ Similar to gels, testosterone solution carries a boxed warning for secondary exposure; however, the subaxillary application site may decrease this risk. It is recommended that patients wash hands immediately after application, and skin-to-skin contact with women and children directly following application should be avoided. ${ }^{42}$

\section{Transbuccal delivery systems}

Transbuccal testosterone was approved by the US FDA in 2003. ${ }^{43}$ This form of administration involves placing a small $30 \mathrm{mg}$ tablet above the teeth on the buccal mucosa twice daily. The testosterone in each tablet is distributed in a matrix containing bioadhesive hydration technology. When administered, the small tablet adheres to the buccal mucosa, forming a gel, at which point the medication is absorbed, thereby avoiding first-pass hepatic metabolism. ${ }^{4}$ Food and beverage consumption does not appear to affect absorption. Serum testosterone peaks 30 minutes after application with a fivefold increase from baseline. ${ }^{4}$ Transbuccal testosterone is generally well tolerated; the most common side effects $(\geq 1 \%$ of patients) include gum or mouth irritation (9.2\%), bitter taste $(4.1 \%)$, gum pain $(3.1 \%)$, gum tenderness $(3.1 \%)$, headache $(3.1 \%)$, gum edema $(2.0 \%)$, and taste perversion $(2.0 \%){ }^{44}$

\section{Intranasal testosterone}

Intranasal testosterone, which was US FDA-approved in 2014, is one of the newest approved therapeutic options for testosterone replacement. ${ }^{45}$ Administered via a metereddose pump, the bioadhesive/gel combination is designed to adhere to the interior lateral wall of the nasal cavity. ${ }^{46,47}$ The gel acts as a controlling matrix, allowing for slow release of testosterone through the nasal mucosa. One pump delivers $5.5 \mathrm{mg}$ of testosterone; the recommended dose is $11 \mathrm{mg}$, intranasally (two pump actuations, one per nostril), three times per day for a total daily dose of $33 \mathrm{mg} .{ }^{46}$ In the registration trial for intranasal testosterone, $90 \%$ of patients had testosterone levels within the normal range after 90 days of treatment. ${ }^{46}$ Information on durability of effectiveness beyond 90 days is not yet available. The most common side effects in clinical studies (incidence $\geq 3 \%$ ) are as follows: increased PSA (5.1\%), headache (3.8\%), rhinorrhea $(3.8 \%)$, epistaxis $(3.8 \%)$, nasal discomfort $(3.8 \%)$, nasopharyngitis $(3.8 \%)$, bronchitis $(3.8 \%)$, upper respiratory tract infection (3.8\%), sinusitis (3.8\%), and nasal scab $(3.8 \%) .{ }^{48}$ Use is not recommended for patients with chronic nasal conditions or alterations in nasal anatomy.

\section{Emerging testosterone therapy}

While many agents are currently being investigated as potential therapies for hypogonadism, this review focuses 
Table 2 Emerging testosterone therapies

\begin{tabular}{|c|c|c|}
\hline Formulation/route & $\begin{array}{l}\text { Dosing } \\
\text { ranges }\end{array}$ & $\begin{array}{l}\text { Dosing } \\
\text { frequency }\end{array}$ \\
\hline \multicolumn{3}{|l|}{ Phase III } \\
\hline $\begin{array}{l}\text { Subcutaneous self-administered } \\
\text { testosterone }^{50}\end{array}$ & $50-100 \mathrm{mg}$ & Once weekly \\
\hline Oral testosterone undecanoate ${ }^{53,55}$ & $100-300 \mathrm{mg}$ & Twice daily \\
\hline Testosterone gel ${ }^{58}$ & $50 \mathrm{mg}$ & Once daily \\
\hline \multicolumn{3}{|l|}{ Phase II } \\
\hline Unmodified oral testosterone $e^{61}$ & $120-240 \mathrm{mg}$ & Twice daily \\
\hline Spray-on testosterone ${ }^{64}$ & $10-70 \mathrm{mg}$ & Once daily \\
\hline
\end{tabular}

on therapies that are under or recently completed Phase II and III study (Table 2).

\section{Phase III}

\section{Subcutaneous self-administered testosterone}

A proprietary, prefilled, subcutaneous auto-injector for selfadministration of testosterone is currently under clinical investigation by Antares Pharma, Inc. (Ewing, NJ, USA). ${ }^{49} \mathrm{Par}-$ ticipants are enrolled in a double-blind, multiple-dose, Phase III study to evaluate efficacy and safety. ${ }^{49}$ The study will enroll approximately 150 men with hypogonadism. Participants will be assigned a starting dose once weekly for 6 weeks and then the dose will be adjusted. ${ }^{49}$ Adjustments to dose may be made at week 7 based upon the week 6 predose blood level. ${ }^{49}$ The primary outcome of the study is the percentage of patients within normal testosterone range after 12 weeks. ${ }^{50}$

Phase II study results for the subcutaneous self-administered testosterone autoinjector were positive. ${ }^{51}$ Specifically, $50 \mathrm{mg}$ and $100 \mathrm{mg}$ doses of self-administered testosterone enanthate delivered via autoinjector were able to rapidly restore and consistently maintain normal testosterone levels in a doseproportionate manner. The once-weekly injection was generally well tolerated and virtually no injection site pain was reported. Another study is planned to collect additional safety data. ${ }^{52}$

\section{Oral testosterone undecanoate}

Two oral TU therapies have completed or are currently under Phase III investigation. ${ }^{53-55}$

Oral TU softgel capsules for twice-daily dosing (Clarus Therapeutics, Inc., Northbrook, IL, USA) has completed Phase IIIa and Phase IIIb trials (NCT01403116 and NCT01765179, respectively) and a New Drug Application was submitted to the US FDA on January 3, 2014..$^{53,56}$ On September 18, 2014, the US FDA Bone, Reproductive and Urologic Drugs Advisory Committee and Drug Safety and Risk Management Advisory Committee voted 18-3 that the overall benefit/risk profile of the oral TU softgel capsules was not acceptable to support approval for TRT. The panel also voted 12-8 with one abstention that evidence showing that the product is effective is insufficient. Although the US FDA is not required to follow the committee's decision, it will consider the findings while reviewing the New Drug Application. ${ }^{56}$ The Phase IIIa trial evaluated the response of 325 hypogonadal men randomized to oral TU softgel capsules twice daily (total of 100-300 mg daily) or a control group treated with a testosterone gel. In this trial, the product reportedly achieved the US FDA guidance for efficacious TRT, defined as at least $75 \%$ of evaluable subjects with a serum testosterone level within the normal range of 300-1,000 $\mathrm{ng} / \mathrm{dL}$. The Phase IIIB trial was a single-arm, 114-day trial conducted in 144 hypogonadal men who received oral TU softgel capsules twice daily (total of 100-300 mg daily). In this trial, serum testosterone concentrations were also normalized in $75 \%$ of men participating in the Phase IIIb trial and "were closely aligned with, but did not precisely meet, the FDA's target for peak testosterone concentrations". 53,56 Most common treatment-related side effects in clinical studies were occasional mild gastrointestinal disturbances in some subjects and a modest decrease in high-density lipoprotein cholesterol. Side effects associated with the drug included increases in hematocrit, enlargement of the prostate or increases in prostate-specific antigen (PSA).

Oral TU for twice-daily dosing (LPCN 1021) is being developed by Lipocine Inc. (Salt Lake City, UT, USA)..$^{54,55}$ Patients are currently enrolled in a Phase III study to determine the safety and efficacy of LPCN 1021. The study will enroll 300 men with hypogonadism, with 200 assigned to LPCN 1021 and 100 men assigned to testosterone gel 1.62\%. The LPCN 1021 study group will receive $225 \mathrm{mg}$ of the drug twice daily, which may be titrated up to $300 \mathrm{mg}$ twice daily or down to $150 \mathrm{mg}$ twice daily (based on serum testosterone levels at weeks 3 and 7). The primary outcome of the Phase III study is the proportion of LPCN 1021 subjects who achieve a total testosterone concentration between 300 and 1,400 ng/ dL following 13 weeks of treatment. ${ }^{54,55}$

\section{Testosterone gel}

The testosterone gel was developed using Advanced Transdermal Delivery ${ }^{\mathrm{TM}}\left(\mathrm{ATD}^{\mathrm{TM}}\right)$ gel technology to achieve rapid transdermal absorption and improved testosterone bioavailability. Applied with an applicator, ATD $^{\mathrm{TM}}$ technology utilizes a combination of solvents and permeation enhancers that facilitate the rapid passage of active agents across the skin. This may lead to lower doses/smaller volumes that reduce the potential for secondary transference..$^{58}$ The primary 
Table 3 Potential cardiovascular risks and benefits of testosterone

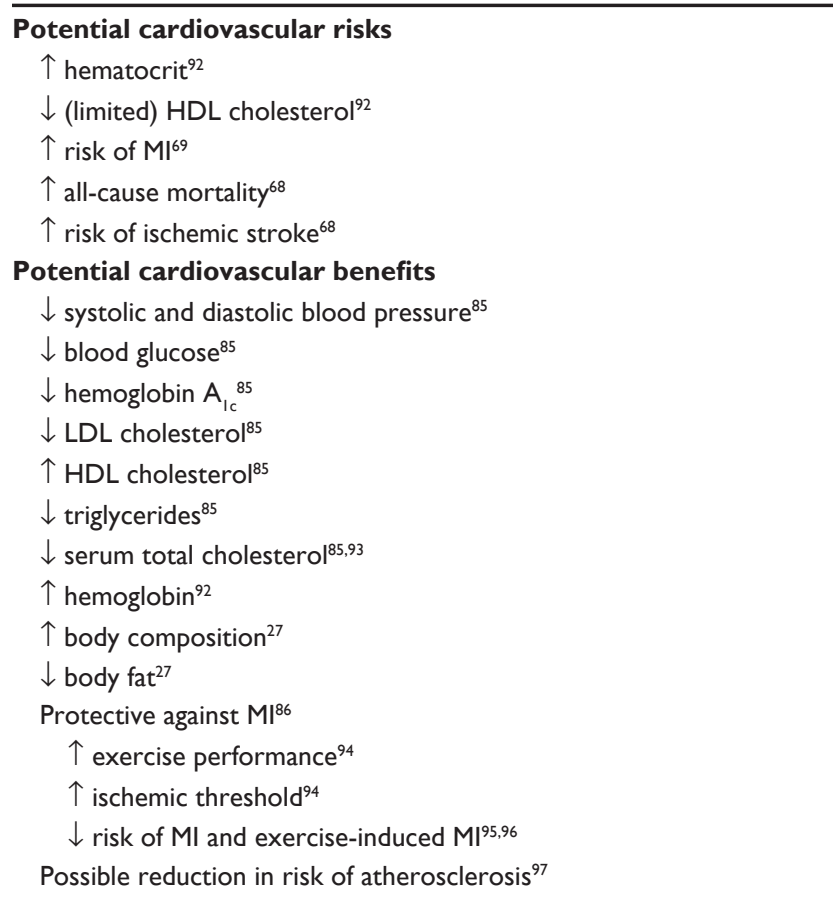

Abbreviations: $\uparrow$, increased; $\downarrow$, decreased; HDL, high-density lipoprotein; MI, myocardial infarction; LDL, low-density lipoprotein.

objective of the Phase III study is to determine the percentage of subjects whose average concentration serum total testosterone levels are within the normal range. ${ }^{57}$

The gel demonstrated favorable results in a Phase II study ${ }^{58,59}$ The Phase II study investigated the pharmacokinetic profile, relative bioavailability, and tolerability of the new testosterone gel $1 \%$ and $2 \%$, in comparison to another approved testosterone gel. The new testosterone gel formulation exhibited higher testosterone bioavailability and faster absorption versus the comparator. ${ }^{58,59}$

\section{Phase II}

\section{Unmodified oral testosterone}

Unmodified oral testosterone (TSX-002) is a novel, proprietary proliposomal formulation being developed by TesoRx Pharma, LLC (Menlo Park, CA, USA).$^{60}$ A Phase II trial has been completed ${ }^{61}$ The primary outcome measures were to assess total serum testosterone and the proportion of subjects achieving a 24-hour average total serum testosterone concentration in the eugonadal range after 15 days of twice-daily treatment. ${ }^{61}$ In a Phase I study, TSX-002 was well tolerated with no liver toxicity or supraphysiological testosterone levels. ${ }^{62}$

\section{Spray-on testosterone}

Spray-on testosterone is being developed by Transdermal Delivery Solutions Corp (Palm Beach Gardens, FL,
USA). ${ }^{63}$ Doses of micronized testosterone are delivered via a new liquid transdermal delivery solution, HydroSpray ${ }^{\mathrm{TM}}$, a metered pump spray. ${ }^{64,65}$ A Phase II study is currently enrolling to establish the efficacy of delivering testosterone rapidly across intact skin. ${ }^{64}$ The primary outcome is to measure response to varying doses $;{ }^{64} 10 \mathrm{mg}, 30 \mathrm{mg}, 50 \mathrm{mg}$, and $70 \mathrm{mg}$ of micronized testosterone are delivered by a new liquid transdermal delivery solution once daily for 7 days or until halted. A previous study in healthy adult males indicated that this transdermal spray can deliver testosterone systemically, and concentrations 12 hours postdose were bioequivalent to an existing topical delivery gel. ${ }^{65}$

\section{Conclusion}

Although current TRT modalities continue to be used safely and effectively, unmet treatment needs exist. Many patients discontinue treatment over time; ${ }^{66,67}$ this patient attrition phenomenon is likely due to a number of factors. Current options carry a risk of secondary exposure, are perceived as inconvenient or are considered painful to administer, are associated with fluctuations in serum testosterone levels, and have been associated with serious safety concerns, such as increased risk for prostate cancer and CV risk. ${ }^{4,8,19,28,39,42,68-70}$

Benign prostate hyperplasia and prostate cancer are more common among older males; however, the effect of TRT on the risk for developing these disorders has been the subject of much debate. ${ }^{28}$ Some physicians are concerned that exogenous testosterone could increase the risk for developing benign prostate hyperplasia and prostate cancer because androgens are essential to prostate growth, and prostate cancers are uncommon among hypogonadal men and castrated males. ${ }^{4,28}$ Research into the relationship between TRT and diseases of the prostate is conflicting. In a compilation of studies involving men receiving TRT, prostate cancer incidence was similar to the general population. A case-control study showed that patients with prostate cancer had lower levels of androgen bioactivity compared to the control group. ${ }^{71}$ Furthermore, an observational study of men who were treated with TRT and who subsequently developed prostate cancer demonstrated that testosterone use was not associated with aggressive prostate cancer and did not affect overall or disease-specific mortality. ${ }^{72}$ However, in another study, subjects with higher levels of serum-free testosterone were associated with an increased risk of prostate cancer. ${ }^{73}$ Despite this conflicting evidence, the majority of studies demonstrate no correlation between increased testosterone levels and the incidence of prostate cancer. ${ }^{74,75}$ Nevertheless, TRT remains contraindicated in 
patients with prostate cancer, and guidelines recommend periodic follow-up of patients, including routine prostate examination and regular monitoring of PSA levels. ${ }^{3}$ Beyond the effects of TRT on the prostate, other urological considerations include potential exacerbation of lower urinary tract symptoms. However, in a recent retrospective study of an outpatient database ${ }^{76}$ initiating TRT in hypogonadal men was found to involve a low risk of worsening lower urinary tract symptoms.

In addition to the debate regarding a potential relationship with TRT and diseases of the urological system, the impact of testosterone on the CV system also remains highly controversial. Recent studies, such as those by Vigen et al, ${ }^{68}$ Finkle et al, ${ }^{69}$ and Basaria et al, ${ }^{70}$ concluded that the use of testosterone therapy was associated with increased risk of adverse $\mathrm{CV}$ outcomes, including mortality, myocardial infarction (MI), or ischemic stroke (Table 3). The studies reporting the increased risk have several limitations: these studies were retrospective; they lacked information on the patients' CV history and time of blood draw, follow-up of blood levels, and information on the serologic or diagnostic indications for treatment; they contained a small sample size; and/or CV events were not the primary outcome of the study. ${ }^{68-70}$ Nevertheless, the findings prompted the US FDA to issue a safety bulletin on testosterone products in January $2014 .{ }^{77}$ The US FDA is currently investigating the risk of mortality, MI, and stroke in men taking US FDA-approved testosterone products, and will communicate final conclusions and recommendations when the evaluation is complete. ${ }^{77}$ According to the bulletin, the agency has not concluded that testosterone agents increase risk of these CV events. ${ }^{77}$ Since the US FDA bulletin was released, the US FDA Bone, Reproductive and Urologic Drugs Advisory Committee (BRUDAC) members expressed interest in additional $\mathrm{CV}$ data to better understand the TRT-CV relationship. The US FDA acknowledged that current data are inconclusive. ${ }^{78}$ Also, following the release of the FDA bulletin, the Vigen et al ${ }^{68}$ study has undergone published corrections for allegedly misreporting data. ${ }^{79}$ In March 2014, 25 international medical societies representing endocrinology, andrology, men's health, and sexual medicine groups joined the Androgen Study Group to petition The Journal of the American Medical Association (JAMA) to retract the article by Vigen et al due to "gross data mismanagement". ${ }^{80}$ The article has reportedly created "enormous damage" and an "unfounded negative perception of testosterone therapy", which has led to treatment discontinuations, harmed physician-patient relationships, and bred a new field of medical malpractice ${ }^{80}$ To date, there has been no published evidence to suggest that patients taking testosterone therapy should discontinue treatment. Additionally, no manufacturer's trial, in which subjects undergo rigorous monitoring, has determined an increased risk of CV events. Despite the aforementioned concerns and ongoing investigation into a potential association between CV events and testosterone therapy, the presence of low testosterone has been correlated with CV risk factors. ${ }^{81,82}$ For instance, observational data suggest that hypogonadism may be associated with metabolic syndrome.$^{83}$ Furthermore, hypogonadism may predispose men to obesity, insulin resistance, hypertension, and abnormal lipid profiles. ${ }^{84}$ Other studies suggest that testosterone therapy has no effect or a protective effect on a patient's CV system. For example, Traish et al ${ }^{85}$ concluded that testosterone therapy improves metabolic syndrome components. Testosterone therapy reduced total cholesterol, low-density lipoprotein cholesterol, triglycerides, and increased high-density lipoprotein cholesterol, as well as reduced blood pressure and hemoglobin $\mathrm{A}_{1 \mathrm{c}}\left(\mathrm{HbA}_{1 \mathrm{c}}\right)$. Moreover, Baillargeon et a ${ }^{86}$ concluded that testosterone therapy was not associated with an increased risk of MI. Testosterone therapy appeared to induce a protective effect against MI for men at highest risk for MI. The current body of literature suggests that the association between testosterone therapy and CV risk or benefit remains inconclusive and requires further investigation. ${ }^{87}$

Another factor to consider with regard to safety of TRT is the potential for TRT to elevate estrogens, specifically estradiol (E2). During testosterone replacement, E2 may increase and, in some cases, exceed the upper limit of normal, which may contribute to the development of nipple or breast tenderness or frank gynecomastia. ${ }^{88}$ However, increases in E2 above the normal range are uncommon and may resolve over time with prolonged TRT. ${ }^{88}$

Although the safety profiles of available testosterone therapies - particularly with regard to CV risk - are still being defined, the known limitations that exist among these therapies, such as the risk of secondary exposure, inconvenient or painful administration, and fluctuations in testosterone serum levels, underscore a need for new options. New therapies should restore testosterone levels safely, with minimal variability, and they should be easy to administer. The future of TRT appears promising, with the expansion of new delivery systems and routes of administration, including a novel and convenient subcutaneous option. These options will further enhance the ability of the clinician to determine the needs of each patient and recommend the most appropriate therapy. 


\section{Acknowledgments}

This work was supported by a grant from Antares Pharma. The content of this article has not been influenced by the sponsor. Medical writing and editorial assistance was provided by AXON Communications (http://www.axon-com. com).

\section{Author contributions}

The authors contributed equally to the development of this manuscript, including conception and design, analysis and interpretation of the literature, writing, critical review and subsequent revisions, final approval of the version to be published, and accountability for all aspects of the work in ensuring that questions related to accuracy and integrity are appropriately investigated and resolved.

\section{Disclosure}

JC Kaminetsky is a speaker and consultant for Auxilium Pharmaceuticals. He is also an investigator for Lipocine Inc., Clarus Therapeutics, Antares Pharma, Inc., Auxilium Pharmaceuticals, and Eli Lilly and Company. Furthermore, he serves as an investigator, speaker, and consultant for AbbVie Pharmaceuticals. The authors report no other conflicts of interest in this work.

\section{References}

1. Bagatell CJ, Bremner WJ. Androgens in men - uses and abuses. N Engl J Med. 1996;334(11):707-714.

2. Jameson JL, De Groot LJ. Endocrinology: Adult and Pediatric. 6th ed. Philadelphia, PA: Saunders; 2010.

3. Bhasin S, Cunningham GR, Hayes FJ, et al; Task Force, Endocrine Society. Testosterone therapy in men with androgen deficiency syndromes: an Endocrine Society clinical practice guideline. $J$ Clin Endocrinol Metab. 2010;95(6):2536-2559.

4. Edelstein D, Sivanandy M, Shahani S, Basaria S. The latest options and future agents for treating male hypogonadism. Expert Opin Pharmacother. 2007;8(17):2991-3008.

5. Harman SM, Metter EJ, Tobin JD, Pearson J, Blackman MR; Baltimore Longitudinal Study of Aging. Longitudinal effects of aging on serum total and free testosterone levels in healthy men. Baltimore Longitudinal Study of Aging. J Clin Endocrinol Metab. 2001;86(2):724-731.

6. Morley JE, Kaiser FE, Perry HM 3rd, et al. Longitudinal changes in testosterone, luteinizing hormone, and follicle-stimulating hormone in healthy older men. Metabolism. 1997;46(4):410-413.

7. Feldman HA, Longcope C, Derby CA, et al. Age trends in the level of serum testosterone and other hormones in middle-aged men: longitudinal results from the Massachusetts male aging study. J Clin Endocrinol Metab. 2002;87(2):589-598.

8. Nieschlag E. Testosterone treatment comes of age: new options for hypogonadal men. Clin Endocrinol (Oxf). 2006;65(3):275-281.

9. Araujo AB, Esche GR, Kupelian V, et al. Prevalence of symptomatic androgen deficiency in men. $J$ Clin Endocrinol Metab. 2007;92(11): 4241-4247.

10. Werner CA. The Older Population: 2010. 2010 Census Briefs. Washington, DC: US Department of Commerce, Economics and Statistics Administration, US Census Bureau; 2011. Available from: http://www.census.gov/prod/cen2010/briefs/c2010br-09.pdf. Accessed October 9, 2014.
11. Howden LM, Meyer JA. Age and Sex Composition: 2010. 2010 Census Briefs. Washington, DC: US Department of Commerce, Economics and Statistics Administration, US Census Bureau; 2011. Available from: http://www.census.gov/prod/cen2010/briefs/c2010br-03.pdf. Accessed October 9, 2014.

12. Dandona $P$, Rosenberg MT. A practical guide to male hypogonadism in the primary care setting. Int J Clin Pract. 2010;64(6):682-696.

13. Basaria S. Male hypogonadism. Lancet. 2014;383(9924): 1250-1263.

14. Maggi M, Schulman C, Quinton R, Langham S, Uhl-Hochgraeber K. The burden of testosterone deficiency syndrome in adult men: economic and quality-of-life impact. $J$ Sex Med. 2007;4(4 Pt 1):1056-1069.

15. Shores MM, Matsumoto AM, Sloan KL, Kivlahan DR. Low serum testosterone and mortality in male veterans. Arch Intern Med. 2006;166(15):1660-1665

16. Corona G, Rastrelli G, Monami M, et al. Body weight loss reverts obesity-associated hypogonadotropic hypogonadism: a systematic review and meta-analysis. Eur J Endocrinol. 2013;168(6):829-843.

17. Laaksonen DE, Niskanen L, Punnonen K, et al. The metabolic syndrome and smoking in relation to hypogonadism in middleaged men: a prospective cohort study. J Clin Endocrinol Metab. 2005;90(2):712-719.

18. Axelsson J, Ingre M, Akerstedt T, Holmbäck U. Effects of acutely displaced sleep on testosterone. J Clin Endocrinol Metab. 2005;90(8): 4530-4535.

19. Nieschlag E, Behre HM, Bouchard P, et al. Testosterone replacement therapy: current trends and future directions. Hum Reprod Update. 2004;10(5):409-419.

20. Buvat J, Maggi M, Gooren L, et al. Endocrine aspects of male sexual dysfunctions. J Sex Med. 2010;7(4 Pt 2):1627-1656.

21. Wang C, Cunningham G, Dobs A, et al. Long-term testosterone gel (AndroGel) treatment maintains beneficial effects on sexual function and mood, lean and fat mass, and bone mineral density in hypogonadal men. J Clin Endocrinol Metab. 2004;89(5):2085-2098.

22. Wang C, Swerdloff RS, Iranmanesh A, et al. Effects of transdermal testosterone gel on bone turnover markers and bone mineral density in hypogonadal men. Clin Endocrinol (Oxf). 2001;54(6):739-750.

23. Steidle C, Schwartz S, Jacoby K, Sebree T, Smith T, Bachand R; North American AA2500 T Gel Study Group. AA2500 testosterone gel normalizes androgen levels in aging males with improvements in body composition and sexual function. J Clin Endocrinol Metab. 2003;88(6):2673-2681.

24. Seftel A. Testosterone replacement therapy for male hypogonadism: part III. Pharmacologic and clinical profiles, monitoring, safety issues, and potential future agents. Int J Impot Res. 2007;19(1):2-24.

25. Saad F, Gooren LJ, Haider A, Yassin A. A dose-response study of testosterone on sexual dysfunction and features of the metabolic syndrome using testosterone gel and parenteral testosterone undecanoate. JAndrol. 2008;29(1):102-105.

26. Yassin DJ, Doros G, Hammerer PG, Yassin AA. Long-term testosterone treatment in elderly men with hypogonadism and erectile dysfunction reduces obesity parameters and improves metabolic syndrome and health-related quality of life. $J$ Sex Med. 2014;11(6): 1567-1576.

27. Wang C, Swerdloff RS, Iranmanesh A, et al; Testosterone Gel Study Group. Transdermal testosterone gel improves sexual function, mood, muscle strength, and body composition parameters in hypogonadal men. J Clin Endocrinol Metab. 2000;85(8):2839-2853.

28. Pfeil E, Dobs AS. Current and future testosterone delivery systems for treatment of the hypogonadal male. Expert Opin Drug Deliv. 2008;5(4): $471-481$.

29. Udedibia E, Kaminetsky J. Phase II drugs currently being investigated for the treatment of hypogonadism. Expert Opin Investig Drugs. 2014;23(12):1605-1618.

30. TESTOPEL ${ }^{\circledR}$ (testosterone pellets) [prescribing information]. Rye, NY: Slate Pharmaceuticals, Inc.; 2013.

31. Kaminetsky JC, Moclair B, Hemani M, Sand M. A phase IV prospective evaluation of the safety and efficacy of extended release testosterone pellets for the treatment of male hypogonadism. J Sex Med. 2011;8(4) 1186-1196. 
32. McCullough AR, Khera M, Goldstein I, Hellstrom WJ, Morgentaler A, Levine LA. A multi-institutional observational study of testosterone levels after testosterone pellet $\left(\right.$ Testope $^{\circledR}{ }^{\circledR}$ ) insertion. $J$ Sex Med. 2012;9(2):594-601.

33. Endo Pharmaceuticals. US FDA approves AVEED ${ }^{\mathrm{TM}}$ (testosterone undecanoate) injectable testosterone replacement therapy for men living with hypogonadism, or low-T [press release]. Dublin, Ireland: Endo Pharmaceuticals; 2014 [March 6]. Available from: http://www.endo. com/news-events/press-releases. Accessed October 9, 2014.

34. AVEED $^{\circledR}$ (testosterone undecanoate injection) [prescribing information]. Malvern, PA: Endo Pharmaceuticals; 2014.

35. Nebido ${ }^{\circledR}(1,000 \mathrm{mg} / 4 \mathrm{~mL}$, solution for injection) [prescribing information]. Leverkusen, Germany: Bayer AG; 2008. Available from: http://www.nebido.com/en/prescribing-information.php. Accessed October 9, 2014.

36. ANDRIOL ${ }^{\circledR}$ (testosterone undecanoate capsules) [prescribing information]. Kirkland, QC: Merck Canada Inc.; 2011.

37. ANDRODERM ${ }^{\circledR}$ (testosterone patch) [prescribing information]. Parsippany, NJ: Watson Pharma, Inc.; 2013.

38. Meikle AW, Arver S, Dobs AS, Sanders SW, Rajaram L, Mazer NA. Pharmacokinetics and metabolism of a permeation-enhanced testosterone transdermal system in hypogonadal men: influence of application site - a clinical research center study. J Clin Endocrinol Metab. 1996;81(5):1832-1840.

39. AndroGel $1.0 \%$ (testosterone gel) [prescribing information]. North Chicago, IL: AbbVie Inc.; 2014.

40. Pope HG Jr, Cohane GH, Kanayama G, Siegel AJ, Hudson JI. Testosterone gel supplementation for men with refractory depression: a randomized, placebo-controlled trial. Am J Psychiatry. 2003;160(1): 105-111.

41. US Food and Drug Administration [webpage on the Internet]. Drug approval package: Axiron (testosterone) topical solution, Acrux Pharma Pty Ltd. Silver Spring, MD: US Food and Drug Administration; 2011. Available from: http://www.accessdata.fda.gov/drugsatfda_docs/ nda/2010/022504_axiron_toc.cfm. Accessed August 15, 2014.

42. Axiron (testosterone) [prescribing information]. Indianapolis, IN: Eli Lilly and Company; 2014.

43. Center for Drug Evaluation and Research. Application number: 21-543. Approval letter. Rockville, MD: US Food and Drug Administration; 2003. Available from: http://www.accessdata.fda.gov/drugsatfda_docs/ nda/2003/21-543_Striant_Approv.pdf. Accessed January 13, 2015.

44. Striant (testosterone buccal tablet) [prescribing information]. Chesterbrook, PA: Actient Pharmaceuticals LLC; 2014.

45. Department of Health and Human Services. NDA approval letter [Nadesto]. Silver Spring, MD: US Food and Drug Administration; 2014. Available from: http://www.accessdata.fda.gov/drugsatfda_docs/applette r/2014/205488Orig1s0001tr.pdf. Accessed January 13, 2015.

46. Trimel Pharmaceuticals [webpage on the Internet]. Natesto ${ }^{\mathrm{TM}}$ (testosterone) nasal gel CIII. Mississauga, ON: Trimel Pharmaceuticals Corporation; 2014. Available from: http://trimelpharmaceuticals. com/Products/Natesto-testosterone-nasal-gel. Accessed August 8, 2014.

47. Trimel Pharmaceuticals [webpage on the Internet]. TriVair ${ }^{\mathrm{TM}}$ nasal gel. Mississauga, ON: Trimel Pharmaceuticals; 2014. Available from: http://trimelpharmaceuticals.com/Technology/Nasal-Gel. Accessed October 9, 2014.

48. Natesto (testosterone) nasal gel CIII [prescribing information]. Christ Church, Barbados: Trimel BioPharma SRL; 2014.

49. Antares Pharma, Inc. Antares Pharma announces first patient dosed in phase 3 QuickShot ${ }^{\circledR}$ study evaluating testosterone-deficient adult males [press release]. Ewing, NJ: Antares Pharma, Inc.; 2014 [July 22]. Available from: http://www.antarespharma.com/ files/4814/0604/4482/QuickShot_testosterone_first_patient_dosed_ P3_study.pdf. Accessed October 9, 2014.

50. Antares Pharma Inc. Subcutaneous testosterone replacement efficacy and safety in adult men diagnosed with hypogonadism (STEADY). Available from: http://clinicaltrials.gov/ct2/show/NCT02159469?term=antares\&r ank=7. NLM identifier: NCT02159469. Accessed August 13, 2014.
51. Antares Pharma, Inc. Antares Pharma announces positive results from the Vibex ${ }^{\circledR}$ Quickshot ${ }^{\mathrm{TM}}$ pharmacokinetic study in testosterone deficient men [press release]. Ewing, NJ: Antares Pharma, Inc.; 2014 [February 20]. Available from: http://www.antarespharma.com/files/3314/0000/3220/ Testosterone_release_final.pdf. Accessed October 9, 2014.

52. Antares Pharma, Inc. Antares Pharma announces positive top-line pharmacokinetic results from the Quickshot ${ }^{\circledR}$ phase 3 study in testosterone deficient men [press release]. Ewing, NJ: Antares Pharma, Inc.; 2015 [February 25]. Available from: http://www.antarespharma.com/ files/4714/2486/6835/P3_PK_QST_2-24-15.pdf. Accessed February $25,2015$.

53. Clarus Therapeutics [webpage on the Internet]. Developing a unique oral testosterone therapy. Northbrook, IL: Clarus Therapeutics; 2014. Available from: http://www.clarustherapeutics.com/index.htm. Accessed September 16, 2014.

54. Lipocine Incorporated [webpage on the Internet]. LPCN 1021. Salt Lake City, UT: Lipocine, Inc.; 2015. Available from: http://lipocine. com/pipeline/lpcn-1021/. Accessed January 13, 2015.

55. Lipocine Inc. Safety and efficacy of oral LPCN 1021 in men with low testosterone or hypogonadism (SOAR). Available from: http://clinicaltrials.gov/ct2/show/NCT02081300?term=LPCN+1021\&rank=1. NLM identifier: NCT02081300. Accessed August 11, 2014.

56. Clarus Therapeutics, Inc. Clarus Therapeutics reports FDA Advisory Committees vote on REXTORO ${ }^{\mathrm{TM}}$ for low testosterone in men [press release]. Northbrook, IL: Clarus Therapeutics, Inc.; 2014 [September 18]. Available from: http://www.clarustherapeutics.com/content/ investors-and-media/releases/091814.htm. Accessed December 22, 2014.

57. Ferring Pharmaceuticals. A clinical trial to evaluate the efficacy and safety of testosterone gel in adult hypogonadal males. Available from: http://clinicaltrials.gov/show/NCT02149264. NLM identifier: NCT02149264. Accessed October 9, 2014.

58. Olsson H, Sandström R, Neijber A, Carrara D, Grundemar L. Pharmacokinetics and bioavailability of a new testosterone gel in comparison to Testoge $\mathrm{l}^{\circledR}$ in healthy men. Clinical Pharmacology in Drug Development. 2014;3(5):358-364.

59. Ferring Pharmaceuticals. A clinical trial to evaluate the pharmacokinetics of testosterone gel using an applicator. Available from: http:// clinicaltrials.gov/show/NCT01464879. NLM identifier: NCT01464879. Accessed August 19, 2014.

60. TesoRx Pharma, LLC. TesoRx and CoreRx announce joint venture to manufacture first-in-class oral testosterone drug [press release]. Menlo Park, CA, and Clearwater, FL: TesoRx Pharma, LLC; 2013 [August 28]. Available from: http://www.corerxpharma.com/corerx-blog/corerx-news/ tesorx-and-corerx-announce-joint-venture-to-manufacture-first-in-classoral-testosterone-drug.html. Accessed October 9, 2014.

61. TesoRx Pharma, LLC. Oral testosterone for the treatment of hypogonadism. Available from: Pharma, LLC. NLM identifier: NCT01717768. Available from: http://clinicaltrials.gov/ct2/show/ NCT01717768?term=TSX-002\&rank=1. Accessed August 11, 2014.

62. Powers M. Tesorx crosses all of its 'T's' with $\$ 10 \mathrm{M}$ series B-1. BioWorld Today. 2014;25(150):1-2.

63. Transdermal Delivery Solutions Corp. [webpage on the Internet]. Testagen: advancing pro-anabolic science. Palm Beach Gardens, FL: Transdermal Delivery Solutions Corp; 2014. Available from: http:// www.tdsc.us/lower.php?url=testagen. Accessed August 15, 2014.

64. Transdermal Delivery Solutions Corp. A dose ranging study to examine Testagen $^{\mathrm{TM}} \mathrm{TDS}^{\circledR}$-testosterone 5\% (PARC-T-D). Available from: http:// clinicaltrials.gov/ct2/show/NCT01894308?term=testagen\&rank=1. NLM identifier: NCT01894308. Accessed August 11, 2014.

65. Chik Z, Johnston A, Tucker AT, Chew SL, Michaels L, Alam CA. Pharmacokinetics of a new testosterone transdermal delivery system, TDS-testosterone in healthy males. Br J Clin Pharmacol. 2006;61(3): 275-279.

66. Muram D. Utilization patterns of parenteral testosterone preparations in hypogonadal men aged at least 45 years: The HIM study. Poster presented at: Endocrine Society's 96th Annual Meeting; June 22; 2014; Chicago, IL. Poster SUN-0072. 
67. Roska EA, Wilson J. Testosterone prescribing and persistence trends in the department of defense, 2002-2012: A retrospective analysis. Poster presented at: Academy of Managed Care Pharmacy (AMCP) 26th Annual Meeting; April 3, 2014; Tampa, FL. Poster 53.

68. Vigen R, O’Donnell CI, Barón AE, et al. Association of testosterone therapy with mortality, myocardial infarction, and stroke in men with low testosterone levels. JAMA. 2013;310(17):1829-1836.

69. Finkle WD, Greenland S, Ridgeway GK, et al. Increased risk of nonfatal myocardial infarction following testosterone therapy prescription in men. PLoS One. 2014;9(1):e85805.

70. Basaria S, Coviello AD, Travison TG, et al. Adverse events associated with testosterone administration. $N$ Engl J Med. 2010;363(2): 109-122.

71. Raivio T, Santti H, Schatzl G, et al. Reduced circulating androgen bioactivity in patients with prostate cancer. Prostate. 2003;55(3): 194-198.

72. Kaplan AL, Hu JC. Use of testosterone replacement therapy in the United States and its effect on subsequent prostate cancer outcomes. Urology. 2013;82(2):321-326.

73. Parsons JK, Carter HB, Platz EA, Wright EJ, Landis P, Metter EJ. Serum testosterone and the risk of prostate cancer: potential implications for testosterone therapy. Cancer Epidemiol Biomarkers Prev. 2005;14(9): 2257-2260.

74. Heikkilä R, Aho K, Heliövaara M, et al. Serum testosterone and sex hormone-binding globulin concentrations and the risk of prostate carcinoma: a longitudinal study. Cancer. 1999;86(2):312-315.

75. Morgentaler A. Testosterone replacement therapy and prostate cancer. Urol Clin North Am. 2007;34(4):555-563, vii.

76. Pearl JA, Berhanu D, François N, et al. Testosterone supplementation does not worsen lower urinary tract symptoms. J Urol. 2013;190(5): 1828-1833.

77. US Food and Drug Administration [webpage on the Internet]. FDA drug safety communication: FDA evaluating risk of stroke, heart attack and death with FDA-approved testosterone products. Silver Spring, MD: US Food and Drug Administration; 2014. Available from: http://www.fda. gov/drugs/drugsafety/ucm383904.htm. Accessed October 9, 2014.

78. US Food and Drug Administration. Joint Meeting for Bone, Reproductive and Urologic Drugs Advisory Committee (BRUDAC) and the Drug Safety and Risk Management Advisory Committee (DSARMAC). Silver Spring, MD: US Food and Drug Administration; 2014. Available from: http://www.fda.gov/downloads/AdvisoryCommittees/CommitteesMeetingMaterials/Drugs/ReproductiveHealthDrugsAdvisoryCommittee/ UCM412536.pdf. Accessed October 8, 2014.

79. Vigen R, O’Donnell CI, Barón AE, et al. Association of testosterone therapy with mortality, myocardial infarction, and stroke in men with low testosterone levels [Erratum]. JAMA. 2014;311(9):967.

80. PR Newswire Association LLC [webpage on the Internet]. Twenty-five medical societies join Androgen Study Group to petition JAMA to retract misleading testosterone study. New York, NY: PR Newswire Association LLC; 2014. Available from: http://www.prnewswire.com/ news-releases/twenty-five-medical-societies-join-androgen-studygroup-to-petition-jama-to-retract-misleading-testosterone-study254707661.html. Accessed October 9, 2014.
81. Yeap BB, Hyde Z, Almeida OP, et al. Lower testosterone levels predict incident stroke and transient ischemic attack in older men. J Clin Endocrinol Metab. 2009;94(7):2353-2359.

82. Ohlsson C, Barrett-Connor E, Bhasin S, et al. High serum testosterone is associated with reduced risk of cardiovascular events in elderly men. The MrOS (Osteoporotic Fractures in Men) study in Sweden. J Am Coll Cardiol. 2011;58(16):1674-1681.

83. Miner MM, Sadovsky R. Evolving issues in male hypogonadism: evaluation, management, and related comorbidities. Cleve Clin J Med. 2007;74 Supp1 3:S38-S46.

84. Makhsida N, Shah J, Yan G, Fisch H, Shabsigh R. Hypogonadism and metabolic syndrome: implications for testosterone therapy. J Urol. 2005;174(3):827-834.

85. Traish AM, Haider A, Doros G, Saad F. Long-term testosterone therapy in hypogonadal men ameliorates elements of the metabolic syndrome: an observational, long-term registry study. Int J Clin Pract. 2014;68(3): 314-329.

86. Baillargeon J, Urban RJ, Kuo YF, et al. Risk of myocardial infarction in older men receiving testosterone therapy. Ann Pharmacother. 2014;48(9):1138-1144.

87. Ruige JB, Ouwens DM, Kaufman JM. Beneficial and adverse effects of testosterone on the cardiovascular system in men. J Clin Endocrinol Metab. 2013;98(11):4300-4310.

88. Kacker R, Traish AM, Morgentaler A. Estrogens in men: clinical implications for sexual function and the treatment of testosterone deficiency. $J$ Sex Med. 2012;9(6):1681-1696.

89. $\mathrm{DEPO}^{\circledR}$ testosterone CIII (testosterone cypionate injection, USP) [prescribing information]. New York, NY: Pfizer Inc.; 2014.

90. AndroGel ${ }^{\circledR} 1.62 \%$ (testosterone gel) [prescribing information]. North Chicago, IL: AbbVie Inc.; 2014.

91. FORTESTA ${ }^{\circledR}$ (testosterone) gel for topical use CIII [prescribing information]. Malvern, PA: Endo Pharmaceuticals Inc.; 2014.

92. Fernández-Balsells MM, Murad MH, Lane M, et al. Clinical review 1: adverse effects of testosterone therapy in adult men: a systematic review and meta-analysis. J Clin Endocrinol Metab. 2010;95(6):2560-2575.

93. Malkin CJ, Pugh PJ, Morris PD, et al. Testosterone replacement in hypogonadal men with angina improves ischaemic threshold and quality of life. Heart. 2004;90(8):871-876.

94. Carson CC 3rd, Rosano G. Exogenous testosterone, cardiovascular events, and cardiovascular risk factors in elderly men: a review of trial data. J Sex Med. 2012;9(1):54-67.

95. Mathur A, Malkin C, Saeed B, Muthusamy R, Jones TH, Channer K. Long-term benefits of testosterone replacement therapy on angina threshold and atheroma in men. Eur J Endocrinol. 2009;161(3):443-449.

96. English KM, Steeds RP, Jones TH, Diver MJ, Channer KS. Low-dose transdermal testosterone therapy improves angina threshold in men with chronic stable angina: a randomized, double-blind, placebo-controlled study. Circulation. 2000;102(16):1906-1911.

97. Oskui PM, French WJ, Herring MJ, Mayeda GS, Burstein S, Kloner RA. Testosterone and the cardiovascular system: a comprehensive review of the clinical literature. J Am Heart Assoc. 2013;2(6):e000272.

Research and Reports in Endocrine Disorders

\section{Publish your work in this journal}

Research and Reports in Endocrine Disorders is an international, peerreviewed, open access journal publishing original research, reports, reviews and commentaries on all areas of endocrinology, endocrine disorders and therapeutic interventions. The manuscript management system is completely online and includes a very quick and fair

to read real quotes from published authors.

\section{Dovepress}

Submit your manuscript here: http://www.dovepress.com/research-and-reports-in-endocrine-disorders-journal 